\title{
Screening and Early Diagnosis of Breast Cancer: Assessment of Knowledge and Practical Abilities of Final Year Nursing and Midwifery Students in Health Schools of Ouagadougou
}

\author{
Nayi Zongo', Marthe Sandrine Sanon/Lompo ${ }^{2}$, H. Aboubacar Bambara ${ }^{1}$, \\ Chantal Soma ${ }^{1}$, Bambara Augustin Tozoula ${ }^{1}$, Bonkoungou Gilbert ${ }^{1}$, \\ Adama Sanou', Ahmadou Dem ${ }^{3}$
}

${ }^{1}$ Division of General Surgery and Oncology, Yalgado Ouédraogo University Hospital of Ouagadougou. ${ }^{2}$ Division of Epidemiology and Public Health, Yalgado Ouédraogo University Hospital of Ouagadougou. ${ }^{3}$ Oncology Institute Joliot Curie of Dakar (Senegal).

\begin{abstract}
Objective: The Objective was to assess the knowledge and practical abilities of final year nursing and midwifery students in health schools of Ouagadougou relating to screening and early diagnosis of breast cancer. Methods: This is a cross-sectional, prospective and descriptive observational study conducted from 1st November 2014 to 31 st January 2015. A sample of 403 students was used for this study. Data were collected using an individual questionnaire and were typed on Epi data and then analyzed on SPSS software. Chi-square tests were used to compare the different proportions. The difference is considered to be significant if $p$-value $<0.05$. Results: Three hundred and ninety-nine students filled the questionnaire, i.e. a rate of non-respondents of $1 \%$. All students were aware of the existence of breast cancer. The media (47.8\%) was the main source of information. The level of knowledge of students was satisfactory with frequencies of $83.9 \%$ for risk factors; $91.6 \%$ for clinical signs; $83.4 \%$ for screening methods and $88.1 \%$ for therapeutic terms of breast cancers. However, the focus should be put on the teaching of cancerology and the supervision of students during the internship, must be reinforced. Conclusions: These results attest that the level of students in the knowledge and practical abilities concerning screening and early diagnosis of breast cancer is satisfactory.
\end{abstract}

Keywords: Cancer- breast- knowledge- abilities- practical- students- nurses- midwives- Ouagadougou

Asian Pac J Cancer Care, 2 (3), 47-52

\section{Introduction}

Breast cancer is the most frequent cancer in women [1]. Its dynamic epidemiology reveals a steady increase in its incidence worldwide and mostly in western countries, due to systematic screening mammography [3]. The annual rate of increase of its incidence is estimated at 3.1\% between 1980 and 2010 [3-5]. Breast cancer is the first cause of death in women over the world [6-7]. Systematic screening mammography from the age of 50 and the careful surveillance of women at risk (BRCA1 and BRCA2 mutations) have allowed an early diagnosis in western countries [1]. These actions of screening, primary and secondary prevention, help avoid
Submission Date: 03/24/2017 Acceptance Date: 05/14/2017

some types of cancers, detect others early enough and mostly have a good prognosis [8].

In contrast to Africa, cancers are diagnosed late and stages III and IV are the usual circumstances of discovery $[9,10]$. This is partly due to the lack of facilities, the lack of an effective coordination of screening and prevention methods, and also poverty and ignorance [11].

By taking an interest in factors of late diagnosis, a study conducted at Yalgado Ouedraogo University Hospital of Ouagadougou (CHUYO), revealed a significant correlation between the lateness of diagnosis and the level of knowledge of health agents in peripheral centres, relating to breast cancers [Ouedraogo 2014].

In fact, in accordance with the recommendations of

Corresponding Author:

Dr. Nayi Zongo

Division of General Surgery and Oncology, Yalgado Ouédraogo University Hospital of Ouagadougou.

Email: nayizongo@yahoo.fr 
Alma Atta, our nurses and midwives work in peripheral centres (grade 1) which constitute the interface between the population and the health system [12-13]. They are those who, in most cases, assess the need or not to refer a patient having a breast disease to the upper level.

Consequently, a good knowledge of signs of alert of breast cancers will enable them to refer patients parsimoniously, and contribute to shorten deadlines of diagnosis and improve prognosis.

Thus, we are conducting this assessment survey on the real level of knowledge of final year nursing and midwifery students in health schools of Ouagadougou, to adjust, when necessary, teachings on cancers. This will enable cover the whole national territory with agents able to detect, advise and collaborate with higher levels for an efficient care of breast cancers.

\section{Materials and Methods}

Type and period of study

This is a cross-sectional, prospective and descriptive observational study. This KAP (Knowledge, Attitudes, and Practices) study was conducted from 1st November 2014 to 31 st January 2015, i.e. over three (03) months.

Framework and population of study

It is made up of all final year nursing and midwifery students of health schools of Ouagadougou, Burkina Faso.

\section{Sampling}

There are six (06) health schools in Ouagadougou. Our study concerned three (03) schools having final year nursing and midwifery students. Each school represented a cluster. Clusters A, B and C represented the National School of Public health (ENSP), Wend-Panga and Sainte Edwige respectively. Each cluster is composed of nursing and midwifery students Table 1 .

This is a KAP (Knowledge, Attitudes, and Practices) study. The size of the sample (n) is given by the following formula: $\mathrm{n}_{\mathrm{o}}=\quad$ being $\mathrm{n}_{\mathrm{o}}=384$ students.

In the literature, former similar studies found average ra1 $n_{\circ}=\frac{z 2 \times(p) \times(1-p)}{c 2}$ espondents (k) of $5 \%$ [Belo et al., 2011; Diop et al., 2012]. Considering $n$ the size of our sample

$$
\mathrm{n}=\mathrm{n}_{\mathrm{o}}+\mathrm{k} \% \mathrm{n}_{\mathrm{o}}=\mathrm{n}_{\mathrm{o}}(1+0,05) \text {, being } \mathrm{n}=403
$$

In the sample, the contribution of each school was defined proportionately to the number of final year students in the school. We considered the type of training (nurses and midwives) as a stratum, i.e. 2 strata per school. Each stratum contributes to the sample n proportionately to its size in the school (Figure 1 annex).

\section{Terms of sampling}

It was a random sampling. The list of students served as the basis for the survey. The students that formed the sample $n$ were drawn randomly with one step of survey being equal to 2 and with number 1 as the first number included in the list.

Criteria for inclusion

All final year nursing and midwifery students selected in the sample, and present in the classroom during the survey and have given their approval to participate in the study, were included.

\section{Criteria of non-inclusion}

Were excluded non-respondents (4 students) i.e. a non-respondents rate of $1 \%$.

\section{Data collection}

The instrument of data collection: a data questionnaire composed of closed-ended and semi-closed ended questions served as a tool for registering the data. With a view to adjusting the questionnaire to students and be more vigilant with the filling of variables, a pre-test was done. It consisted in supervising the filling of the questionnaire, while clarifying some terms, in order to avoid any ambiguity in the answers.

\section{Data collection operations}

After getting approval from the administrative heads of the various schools and after being reassured that the students received the course on cancerology, mostly on breast diseases, we went to the schools, according to their availability, to administer the questionnaire. A brief explanation of the objective and even the good purpose of the study preceded the distribution of the survey sheet, then followed the individual filling of the questionnaire over a period of $30 \mathrm{mn}$.

Following this, the students enjoyed a brief interview in the form of slideshow relating to the main knowledge on breast cancers. The information was collected from 1st November 2014 to 31 st January 2015.

\section{Data analysis}

The questionnaires obtained were first typed on Epi Data 2.2 French version, then the data were exported on SPSS software for data cleaning and analysis according to the subjects defined beforehand. The construction of graphs was done by Excel 2013 spreadsheet. To extrapolate the data of the population from those of our sample, confidence intervals at $95 \%$ were calculated. Pearson Chi-square tests were used to compare the various proportions. The difference is considered to be significant if $\mathrm{p}$-value $<0,05$.

\section{Assessment of variables}

Variables related to knowledge: In conformity with the current medical knowledge, the assessment of the level of knowledge was made as follows: false knowledge: inconsistent answer; no knowledge, abstention or lack of answer; average knowledge: 1 or 2 true affirmations; good knowledge: more than 2 true affirmations.

\section{Variables related to the abilities}

The students' abilities were assessed as follows: favorable (answer $=$ yes) with attribution of +1 point, indecisive (answer $=$ don't know) with attribution of 0 point or unfavorable (answer $=$ no) with attribution -1 point. The addition of marks of each variable enabled to assess the overall abilities of the students as follows: mark $>0$ 
corresponds to a favorable answer; Mark $=0$ corresponds to an indecisive answer (neither favorable nor unfavorable); Mark $<0$ corresponds to an unfavorable answer.

Variables related to the practice: For our study, practice defines the behavior, gesture to be made by the student before a suspicious lesion of the breast. It is assessed as follows: No conduct: lack of answer; Bad conduct: inconsistent answer; Good conduct: true answer Ethical considerations: Anonymity of the students was respected. We got the authorization of the various school directors before the study.

\section{Results}

The survey in health schools of the city of Ouagadougou allowed interviewing 399 students i.e. 234 nurses (58.7\%) and 165 midwives $(41.3 \%)$.

All the students interviewed knew that breast cancer exists. The media represented the main source of first information, whatever the type of training (nursing students $=47.90 \%$, midwifery students $=47.60 \%$ with Chi-square $=0.003$ and $\mathrm{P}$. value $=0.954)$. Three hundred and seventy-five (375) students mentioned the frequent or non-frequent nature of breast cancer. Among them, 97.1\% thought that breast cancer was frequent and $86.2 \%$ affirmed that it is the most frequent cancer in women over the world. A proportion of $93.6 \%$ of students thought that cancer is a serious disease and $80.2 \%$ of the students affirmed that it can be avoided. The knowledge of final year nursing and midwifery students does not seem to be influenced by the type of training as far as the frequency and lethality of breast cancer $(\mathrm{P}>0.05)$ are concerned. However, state midwives are significantly in advance concerning the knowledge on prevention (Chi-square $=4.972$ and $\mathrm{P}=0.026$ ) and seriousness (Chi-square $=4.309$ and $\mathrm{P}=0.038$ ) of breast cancer. A total of 335 students i.e. $83.9 \%$ mentioned the transmissible or non-transmissible nature of breast cancer. Among them, 37.01\% thought that breast cancer is non-transmissible and $62.9 \%$ affirmed that it is

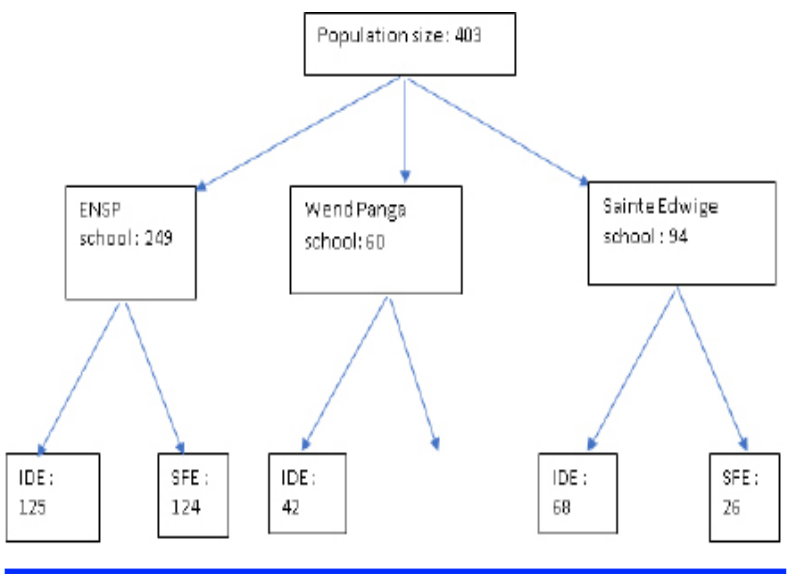

Figure 1. Chart on the Sample's Distribution

ENSP, Ecole Nationale de Santé Publique / National School of Public Health; IDE, infirmiers d'état/State nurses; SFE, sages-femmes d'état / State midwives; Wend Panga and Sainte Edwige, school's names Number

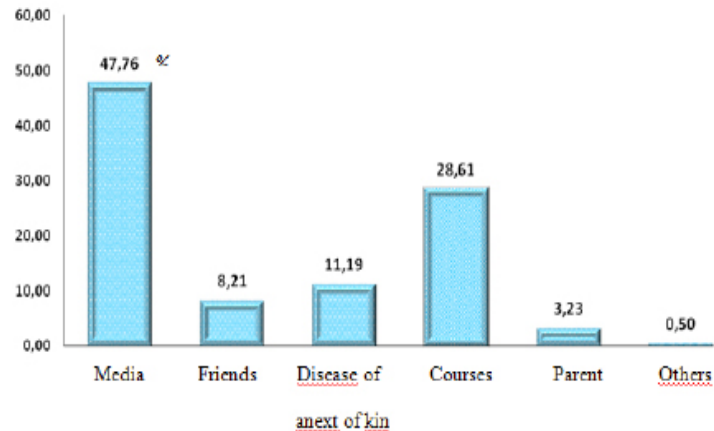

Source of informatio

Figure 2. Distribution of Students According to the Source of Information

a transmissible disease.

A total of 383 students $(95.9 \%)$ commented on the curable or non-curable aspect of breast cancer, in case it is early diagnosed. Among them, 94\% thought that breast cancer is curable when early diagnosed. A total of 351 students $(87.9 \%)$ commented on the curable or non-curable aspect of breast cancer whatever the stage of diagnosis. Only $7.4 \%$ of them affirmed that breast cancer is curable whatever its stage. A total of 363 students $(90.9 \%)$ commented on the risk factors. In $83.9 \%$ of cases, was noted the knowledge of students on risk factors of breast cancer, according to the type of training. The various risk factors were known. Mastopathies were less known as risk factors by newly recruited than by professionals in a statistically significant way (Chi-square $=7.099$ and $\mathrm{P}=0.029)$. It was the same for first late pregnancy (Chi-square $=13.833$ and $\mathrm{P}=0.001$ ).

A total of 265 students i.e. a proportion of $66.4 \%$ affirmed that breast cancer could be detected at a subclinical stage. More than $50 \%$ of the students knew that each health worker is a screening actor in Burkina Faso. A proportion of $81.1 \%$ affirmed that screening should be done when the patient is asymptomatic. This same proportion affirmed that screening should mostly concern women over 50 years, $12.6 \%$ thought that any adult man should also be concerned by screening. A proportion of $72.1 \%$ thought that screening should be done regularly every three years and $95.2 \%$ propose that it is done very often in groups at risk. In $83.4 \%$ of cases, the students knew at least one screening method. The real screening (mammography and X-Ray) were known by almost all the students without a statistically

Table 1. Distribution of Numbers of Students by School and by Type of Training

\begin{tabular}{lccc}
\hline School & State Nurses & State midwives & Total \\
\hline ENSP & 250 & 248 & 498 \\
Wend-Panga & 85 & 35 & 120 \\
Sainte Edwige & 135 & 52 & 187 \\
Total & 470 & 335 & 805 \\
\hline
\end{tabular}

ENSP, Ecole Nationale de Santé Publique / National School of Public Health; IDE, infirmiers d'état/State nurses; SFE, sages-femmes d'état / State midwives 
Table 2. Distribution of Students Depending on Their Knowledge of Risk Factors According to the Type of Training

\begin{tabular}{lccc}
\hline $\begin{array}{l}\text { Type of training } \\
\text { Risk factors }\end{array}$ & State nurses & State midwives & P. value \\
\hline Age $>$ 50 years & 68.8 & 58.2 & 0.069 \\
Female & 93 & 97.1 & 0.104 \\
Mastopathies & 80.3 & 86.7 & 0.138 \\
History of cancer & 82.6 & 76.7 & 0.198 \\
Genetic mutation & 83.9 & 86 & 0.721 \\
Early puberty & 43.5 & 38.1 & 0.35 \\
Late menopause & 45.3 & 34.5 & 0.072 \\
Pauciparity & 12.3 & 18.1 & 0.182 \\
Nulliparity & 28.6 & 38 & 0.087 \\
1st late pregnancy $>35$ years & 45.2 & 36.6 & 0.147 \\
Contraceptive pill & 58.7 & 54.5 & 0.456 \\
Food & 66.9 & 33 & 0 \\
Diabetes/Obesity & 83.9 & 37.7 & 0 \\
Radiations & 78.2 & 84.7 & 0.156 \\
Pesticides & 41.1 & 64.1 & 0 \\
\hline
\end{tabular}

significant difference according to the recruitment way (Chi-square $=2.826$ and $\mathrm{P}=0.248$ ). Other tests not necessary for the screening, like MRI, scanner, chest $\mathrm{X}$-Ray and abdominal X-Ray without preparation, were also mentioned.

In $91.6 \%$ of cases, more than two signs were known by the students. In the table, were summarized the known alert symptoms of breast cancers according to the type of training.

All the students had a good knowledge of breast self-examination, clinical test, X-Ray, and mammography to diagnose breast cancer. However, less that $50 \%$ knew the crucial stages (biopsy, cytology, histology) in the diagnosis of breast cancer. A proportion of $94.5 \%$ of the students knew what breast self-examination means. A major part of the students knew that breast self-examination was monthly $(66.9 \%)$. There was no statistically significant difference depending on the type of training (Chi-square $=1.351$ and $\mathrm{P}=0,509$ ). Less than $50 \%$ of the students $(33,5 \%)$ knew that breast self-examination should be done after menses. There was a statistically significant difference depending on the type of training (Square $\mathrm{Chi}=12.500$ and $\mathrm{P}=0.000$ ).

In $88.1 \%$ of cases, students knew more than two methods of treatment and less than two methods were known in $11.9 \%$ of cases. Nursing students had a statistically better knowledge of therapeutic terms of breast cancers compared to midwives $(\mathrm{P}<0.002)$, apart from palliative care $(\mathrm{P}=0.273)$.

A total of 380 students i.e. $95.2 \%$ affirmed that referral to a specialist was the practical attitude to adopt before a suspicious anomaly on the breast. A proportion of $95.9 \%$ of nurses and $95.1 \%$ of midwives underlined this same attitude $(\mathrm{P}=0.706)$. Furthermore, it was recognized by $94.2 \%$ of students who got admission privately, $100 \%$ of those admitted by direct recruitment through competition and $94.7 \%$ of those admitted as professionals $(\mathrm{P}=0.088)$. Concerning the advice to patients, the students recommended: teach to patients the technique of breast self-examination, encourage to a regular practice and sensitize them to take part in screening campaigns. These were the main advice that a total of 209 students i.e. a proportion of $52.3 \%$ recommended for an early diagnosis of breast cancers.

\section{Discussion}

Over 399 students selected, nurses represented 58.7\% and midwives $41.3 \%$. The respondent's rate in our series was $99 \%$. It is the best rate compared to those of Nigerian authors [14] and Turkish authors [15] who noted $73 \%$ and $80.6 \%$ respectively, of respondents during their surveys on healthcare professionals. This difference may be explained by the rigorous discipline of the training on students through the daily attendance list and the justification of any absence at a course.

All students questioned $(100 \%)$ were informed and aware that breast cancer exists. This may be explained by the rise of NICT (New Information and Communication Technologies) and the real delivery of the course on cancerology in the various schools. This proportion is above the one found in Nigeria and in Saudi Arabia [16, 17] which were $97.1 \%$ and $90 \%$ respectively. The media were the main source of information of students with a frequency of $47.9 \%$ (Chi-square $=0.003$ et $\mathrm{P}=0.954$ ). In Dina et al. (2012) series in Egypt, the media were representing a frequency of $89.1 \%$. in a Nigerian series [18]. courses were the main source of information $(63.7 \%)$ followed by the media with a frequency of $19.7 \%$. Our study reveals that the media constitute the main channel of first information about breast cancer whatever the type of training (midwives or state nurses). A proportion of $97.1 \%$

Table 3. Distribution of Students Depending on Their Knowledge of Warning Signs According to the Type of Training

\begin{tabular}{lccc}
\hline Type of training & State nurses & State midwives & P. value \\
\hline Risk factors & & & \\
Age $>$ 50 years & 68.8 & 58.2 & 0.069 \\
Female & 93 & 97.1 & 0.104 \\
Mastopathies & 80.3 & 86.7 & 0.138 \\
History of cancer & 82.6 & 76.7 & 0.198 \\
Genetic mutation & 83.9 & 86 & 0.721 \\
Early puberty & 43.5 & 38.1 & 0.350 \\
Late menopause & 45.3 & 34.5 & 0.072 \\
Pauciparity & 12.3 & 18.1 & 0.182 \\
Nulliparity & 28.6 & 38 & 0.087 \\
1st late pregnancy $>35$ & 45.2 & 36.6 & 0.147 \\
years & & & \\
Contraceptive pill & 58.7 & 54.5 & 0.456 \\
Food & 66.9 & 33 & 0.000 \\
Diabetes/Obesity & 83.9 & 37.7 & 0.000 \\
Radiations & 78.2 & 84.7 & 0.156 \\
Pesticides & 41.1 & 64.1 & 0.000 \\
\hline & & & \\
\hline
\end{tabular}


of the students thought that breast cancer is a frequent disease and $86.2 \%$ affirmed that it is most frequent cancer in women in the world. This result is similar to that of Bassey et al. (2011) in Nigeria (84.8\%) and Mehregan (2002) in Iran (75\%). In our series, the type of training and the way of recruitment do not seem to have an influence on the general knowledge of students relating to breast cancer $(\mathrm{P}>0,05)$. In contrast, state midwives had a significant advance concerning the knowledge on the prevention and seriousness of breast cancer $(\mathrm{P}<0.05)$. This could be explained by the nature of midwifery profession and the fact that midwives are those who mostly face breast diseases. The level of state nurses could be improved by the reinforcement of the course on cancerology and self-training.

Among the $90.9 \%$ of the respondents who commented on risk factors of breast cancer, $83.9 \%$ had a very good knowledge of risk factors. This level of knowledge was better than those noted in Nigeria [19] and in Morocco [20]. where the authors reported that proportions of 55\% $($ Chi-square $=94.056 ; \mathrm{P}<0.0001)$ and $56.5 \%(\mathrm{P}<0.001)$ respectively of respondents in their series had a poor knowledge of risk factors. In our series, the risk factors known mostly concerned women and mastopathies with frequencies of $94.7 \%$ and $82.9 \%$ respectively. For some authors [15] mastopathies represented only $38.7 \%$ of risk factors known by the respondents. In some series, namely Egyptian and German series [21, 22], family history of cancer was the main risk factor known with (90.2\%) and $(94.9 \%)$ respectively of respondents. Furthermore, our results show that mastopathies and late pregnancies were risk factors less known by students registered at a health school for the first time than by professionals in a statistically significant way $(\mathrm{P}<0.05)$. The experience of healthcare professionals on the ground could well explain this difference in the knowledge of risk factors.

In our series, all students knew at least a method of breast cancer screening. Their level of knowledge of screening methods is satisfactory $(83.4 \%)$. Our results show that the majority (more than $60 \%$ ) of students knew the main methods (mammography, X-ray) necessary for breast cancer screening without a statistically significant difference according to the type of training $(\mathrm{P}>0.05)$. Mammography was highly underlined as a main screening method (99.5\%). Other African surveys conducted with health workers $[17,23]$ noted similar results. However, Maria et al. (2006) in Hong Kong revealed that $58 \%$ of its population of the study had never heard about screening mammography. This difference in the results between authors could be due to the quality of the respondents. Health workers under training, like in our series or those working already have a clear advantage compared to the general population. This shows the place of training in the access to information on breast cancer.

A proportion of $95.2 \%$ of students in our series knew at least one symptom. Their level of knowledge concerning breast cancer warning signs is very satisfactory $(91.6 \%)$. This result can be compared to that of Philippian authors [24] (93\%). Like in several similar studies [3], in our surveyed persons, breast mass was the most known symptom with a frequency of $86.2 \%$. In some series [23], lymphadenopathy was the key symptom (91.9\% ; P $=0.001)$. These two signs (breast mass and axillary lymphadenopathy) are the most known both by health workers and the general population. It is undoubtedly, because it is perceptible and palpable by all, mostly as the breast is a superficial organ. The most discrete signs like mastodynias remain less related to breast cancer according to those surveyed.

All the students had a very good knowledge of breast self-examination practice, breast clinical examination, $\mathrm{X}$-ray and mammography to make the diagnosis of breast cancer. However, their level of knowledge concerning the main tests (biopsy, cytology, histology) in the diagnosis of breast cancer is limited. Clinical breast examination and breast-self examination were less known by the students with frequencies of $87.2 \%$ and $82.7 \%$ respectively. Turkish and Indian authors had also noted a good knowledge of the various steps for the diagnosis by the students with respective proportions of $98.4 \%$ and $89.2 \%$ [15, 25].The good knowledge of diagnosis stages is essential for the fight against breast cancer. In fact, nurses and midwives who are the entry point into the health system will have the reflex to refer patients immediately to the higher level for tests non-available in peripheral centres.

A proportion of $66.9 \%$ of students in our series knew the frequency of breast self-examination, but only $33.5 \%$ knew the best period during the cycle to do it (monthly and 7-10 days after the beginning of menses). Other African surveys like that of [26] in Nigeria also noted a high level of knowledge of students (98.5\%). However, [27] in Angola found that only 50\% of students of their series knew the appropriate time for breast self-examination. In the black African context where systematic screening mammography is not current, due to poverty, a good knowledge of breast self-examination by health workers and women remain the cornerstone for early diagnosis.

$88.1 \%$ of students in our series had a satisfactory knowledge of means of treatment of breast cancer. Surgery and chemotherapy, with respective frequencies of $86.4 \%$ and $81.2 \%$ were the best-known methods. Our results attest that apart from palliative care $(\mathrm{P}=0.273)$, nursing students had a statistically better knowledge of therapeutic terms of breast cancer compared to midwives $(\mathrm{P}=0.002)$. Although nursing and midwifery students will not treat breast cancers, it is crucial for them to be able to know the therapeutic methods, in order to advise the women they will receive in the peripheral health centres.

The patient's referral to a specialist is the practical appropriate attitude to adopt before any suspicious lesion of breast cancer. This attitude was recognized by a proportion of $94.3 \%$ of the students. It was strongly underlined by nurses and midwives $(\mathrm{P}=0.706)$ as well as those who got admission by direct recruitment through competition. There is no significant difference concerning the practical attitude to adopt before a suspicious lesion of the breast according to the way of recruitment $(\mathrm{P}=0.088)$.

In conclusion and recommendation, our study shows that all the students are aware of the existence of breast cancer. The media and courses are the main sources of 
information. It results that the level of knowledge of students concerning risk factors, clinical signs, screening methods and the treatment of breast cancer is quite high. Moreover, their attitude before a suspicious lesion is good. Their knowledge of methods of breast cancer early diagnosis and breast self-examination still has to be improved. We should, therefore, stay the course on education and improve practical training.

\section{References}

1. Cancer du sein: prévention et Lutte contre la maladie. www.who.int/topics/cancer/breastcancer/fr/. Accessed August 11, 2017 (2017).

2. Traore SS ZM, Lamien/Sanou A.Le cancer du sein au CNHYO. Aspects épidémiologiques à propos de 138 case. Burkina Med.;. (2005);8((2):):35-40.

3. Opoku SY BM, Yarney J . Knowledge, attitudes, beliefs, behavior and breast cancer screening practices in Ghana, West Africa. University of Ghana, Accra. Pan Afric Med $\mathrm{J} ;(2012) ; 11:: 28-32$.

4. Bouchbika Z SZ, Sahraoui S, Othmani BM, Benider AStade du cancer du sein Lors du diagnostic: impact des Campagnes de sensibilisation. Prat Organ Soins.; . (2012).;43 ((4): ):269-75.

5. Ghanem S GM, Elkhoyaali S, et al. Pan Afr Med J. Knowledge of risk factors, beliefs and practices of female healthcare professionals towards breast cancer, Morocco. (2011);10((21): ): 1-10.

6. Maria RS MA, Rocio M, Richard Ah, Lovell AJ Assessing breast cancer knowledge, beliefs and misconceptions among Latinas in Houston, Texas. J of Cancer Education, . (2016); 21 ((1): ): 42-6.

7. Sarfo LAAPD, Acheampong E, et al. Knowledge, attitude, and practice of self-breast examination among female university students at Presbyterian University College, Ghana. American J of Res-Com;. (2013);1 ((11): ): 395-404.

8. Ohene-Yeboah M, Adjei E. Breast cancer in Kumasi, Ghana. Ghana medical journal. 2012;46(1):8-13.

9. Forouzanfar MH, Foreman KJ, Delossantos AM, Lozano R, Lopez AD, Murray CJ, et al. Breast and cervical cancer in 187 countries between 1980 and 2010: a systematic analysis. Lancet (London, England). 2011;378(9801): 1461-84.

10. Rosmawati NH. Knowledge, attitudes, and practice of breast self-examination among women in a suburban area in Terengganu, Malaysia. Asian Pacific journal of cancer prevention: APJCP. 2010;11(6):1503-8.

11. Sreedharan J, Muttappallymyalil J, Venkatraman M, Thomas M. Breast self-examination: knowledge and practice among nurses in the United Arab Emirates. Asian Pacific journal of cancer prevention: APJCP. 2010;11(3):651-4.

12. I O. Diagnostic Tardif du cancer du sein au CHU Yalgado Ouédraogo de Ouagadougou, BF: Facteurs, impacts thérapeutiques et pronostiques. A proposed de 70 case. Thèse de médecine, UFR/Science de la Santé, Université de Ouagadougou, (2014).

13. Diop PS KI, Ndiaye N, Fall B Cancers gynécologiques et mammaires à l'hôpital général de Grand-Yoff de Dakar: analyze et implications des aspects épidémiologiques à propos de 169 case. J Afr Can;. (2012). ;4 ( (3):):176-9.

14. Odusanya OO TO. Breast cancer knowledge, attitudes, and practice among nurses in Lagos, Nigeria. Oncol
Nurs Forum.; (2003). 659-67. p.

15. Yeliz YA ZB, Melis N, Iskender G, Fevziye C Knowledge, Attitude about Breast Cancer and Practice of Breast Cancer Screening among Female Health Care Professionals: A Study from Turkey. Asian Pacific J Cancer Prev; (2011);12, :3063-8.

16. Elhshamyl KF SA. Knowledge and Practice of Breast Cancer screening among Egyptian Nurses.Afr J Haematol Oncol; (2010); 1 ((4) : ): 122-8.

17. Saeedi MY AF, Khair IA, Kassim K Knowledge, attitude and practice of breast cancer screening among female general practitioners in Riyadh, Saudi Arabia. Can Res J;. (2014);2 ((6): ): 108-13.

18. Utoo PM CO. Knowledge, practices and education of clients regarding breast cancer screening among healthcare workers in the plateau, north-central Nigeria. Jos J of Med; (2012). 6( (2):):46-9.

19. Akhigbe AO, Omuemu VO. Knowledge, attitudes, and practice of breast cancer screening among female health workers in a Nigerian urban city. BMC cancer. 2009;9:203.

20. Goumbri/Lompo OM DO, Sanou A, Konsegre V, Soudre RBAspects épidemiologiques et histopathologies des cancers au Burkina Faso. J Afr Can; (2009).1( (4):): 207-11.

21. M E. Diagnostic et décision dans le cancer du sein à un stade précoce. Springer, Paris ; (2012).

22. Pohls UG, Renner SP, Fasching PA, Lux MP, Kreis $\mathrm{H}$, Ackermann S, et al. Awareness of breast cancer incidence and risk factors among healthy women. European journal of cancer prevention: the official journal of the European Cancer Prevention Organisation (ECP). 2004;13(4):249-56.

23. Bello TO, Olugbenga-Bello AI, Oguntola AS, Adeoti ML, Ojemakinde OM. Knowledge and practice of breast cancer screening among female nurses and laywomen in Osogbo, Nigeria. West African journal of medicine. 2011;30(4): 296-300.

24. Ngelangel CA, Ordono ML, Lu-Lim J, Fernandez RA. Knowledge, attitudes, and practices on breast cancer and breast examination of nurses and midwives in Metro Manila. Philippine Journal of internal medicine. 1997;35(1):15-7.

25. Sujindra E ET. Knowledge, attitude, and practice of breast self-examination in female nursing students (India). Int J Educ Psychol Res;. (2015). ;1::71-4.

26. Bassey RB IN, Olowoyeye MA, Adekunle AA, Adebayo TO Knowledge, attitude and practice of breast self-examination among nursing students in Lagos University Teaching Hospital, Nigeria. Intern Res J; (2011).2( (6) :):1232-6. .

27.Sambanje MN, Mafuvadze B. Breast cancer knowledge and awareness among university students in Angola. The Pan African medical journal. 2012;11:70.

This work is licensed under a Creative Commons AttributionNon Commercial 4.0 International License. 